\title{
CONFLICT OF INTEREST COMPLIANCE ARTICLE 4
}

As is standard in scholarly publishing, NCSBN's Journal of Nursing Regulation (JNR) requires its authors to disclose any potential conflicts of interest (COI). Although COI information has always been collected by

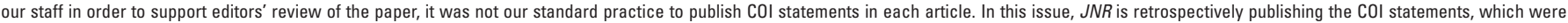
collected with the below papers at submission, in order to make potential COl's transparent to readers, as well as editors.

1. "The Interdisciplinary Research Group on Nursing Issues: Advancing Health Services Research, Policy, Regulation, and Practice" ing Health Services Research, Policy, Regulation, and Practice"
[Journal of Nursing Regulation, 2019;10(2):55-59] https://doi. [Journal of Nursing Regulation,
org/10.1016/S2155-8256(19)30116-4

org/10.1016/S2155-8256(19)30116-4 Declaration of competing interest: The authors declare the following financial interests/personal relationships which may be considered as potential competing interests: Squires was a paid editor for the Journal of Nursing Regulation when this was published. All other authors have no conflicts of interest.

2. "Section 1557 of the Affordable Care Act: Strengthening Language Access Rights for Patients With Limited English Proficiency" [Journal of Nursing Regulation, 2019;10(1):65-67] https://doi.org/10.1016/ S2155-8256(19)30085-7

Declaration of competing interest: The authors declare that they have no known competing financial interests or personal relationships that could have appeared to influence the work reported in this paper.

3. "Enhancing Psychiatric Mental Health Nurse Practitioner Practice: Impact of State Scope of Practice Regulations" [Journal of Nursing Regulation, 2019;10(1):35-43] https://doi.org/10.1016/ S2155-8256(19)30081-X

Declaration of competing interest: The authors declare that they have no known competing financial interests or personal relationships that could have appeared to influence the work reported in this paper.

4. "Mitigating Responses to the Opioid Crisis" [Journal of Nursing Regulation, 2019;10(1):57-64] https://doi.org/10.1016/ S2155-8256(19)30084-5

Declaration of competing interest: The authors were contacted after publication to request a Declaration of Interest statement.
5. "Nursing Staff Availability and Other Facility Characteristics in Relation to Assisted Living Care Deficiencies" [Journal of Nursing Regu-
lation, 2019;10(1):21-27] http s://d oi.org/10.1016 lation, 2019;10(1):2

Declaration of competing interest: The authors were contacted after publication to request a Declaration of Interest statement.

6. "States Introduce New Occupational Licensure Bills to Support Military Spouses and Beyond" [Journal of Nursing Regulation 2019;10(3):62-63] https://doi.org/10.1016/S2155-8256(19)30149-8 Declaration of competing interest: The authors were contacted afte publication to request a Declaration of Interest statement.

7. "An Evaluation Process to Redesign the North Carolina AHEC Reg istered Nurse Refresher Program" [Journal of Nursing Regulation, 2019;10(2):38-44] https://doi.org/10.1016/S2155-8256(19)30114-0 Declaration of competing interest: The authors were contacted after publication to request a Declaration of Interest statement.

8. "The Regulatory Implications of Engaging Registered Nurses in Diagnoses" [Journal of Nursing Regulation, 2019:10(2):5-10] https://doi. org/10.1016/S2155-8256(19)30110-3

Declaration of competing interest: The authors were contacted after publication to request a Declaration of Interest statement.

9. "The Growth and Performance of Nursing Programs by Ownership Status" [Journal of Nursing Regulation, 2019;9(4):5-21] https://doi. Status" [ Journal of Nursing Regul
org/10.1016/S2155-8256(19)30011-0

org/10.1016/S2155-8256(19)30011-0
Declaration of competing interest: The authors were contacted after Declaration of competing interest: The authors were contac

10. “Who Drafted That? Model Legislation Impacting Nursing and Regulation" [Journal of Nursing Regulation, 2019;10(2):60-63] https://do org/10.1016/S2155-8256(19)30117-6

Declaration of competing interest: The authors were contacted after publication to request a Declaration of Interest statement.
11. "International Clinical Experiences for Required Clinical Hours: National Survey of Registered Nurse Pre-licensure Programs" [Journal of Nursing Regulation, 2019; Volume (Issue):53-56] https://doi. org/10.1016/S2155-8256(19)30083-3

Declaration of competing interest: The authors were contacted after publication to request a Declaration of Interest statement.

12. "Regulation of the Nurse Practitioner Workforce: Implications for Care Across Settings" [Journal of Nursing Regulation, 2019;10(2):3137] https://doi.org/10.1016/S2155-8256(19)30113-9

Declaration of competing interest: The authors were contacted after publication to request a Declaration of Interest statement.

13. “How Off-Duty Use of Social Media May Lead to Professional Discipline" [Journal of Nursing Regulation, 2019;9(4):31-33] https://doi. org/10.1016/S2155-8256(19)30013-4

Declaration of competing interest: The authors were contacted after publication to request a Declaration of Interest statement.

14. "When Is Accessing Medical Records a HIPAA Breach?" [Journal of Nursing Regulation, 2019;10(3):34-36] https://doi.org/10.1016/ S2155-8256(19)30146-2

Declaration of competing interest: The authors were contacted after publication to request a Declaration of Interest statement.

15. “The Economic Impact of the Expansion of Nurse Practitioner Scope of Practice for Medicaid" [Journal of Nursing Regulation, 2019;10(1):15-20] https://doi.org/10.1016/S2155-8256(19)30078-X Declaration of competing interest: The authors were contacted after publication to request a Declaration of Interest statement. 